\title{
A Simple and Cost-Saving Approach To Optimize the Production of Subtilisin NAT by Submerged Cultivation of Bacillus subtilis Natto
}

\author{
Ting-Wei Ku, Ruei-Lan Tsai, and Tzu-Ming PaN* \\ Institute of Microbiology and Biochemistry, National Taiwan University, \\ Taipei 10617, Taiwan, Republic of China
}

\begin{abstract}
Subtilisin NAT, formerly designated nattokinase or subtilisin BSP, is a potent cardiovascular drug because of its strong fibrinolytic activity and safety. In this study, one Bacillus subtilis natto strain with high fibrinolytic activity was isolated. We further studied the optimal conditions for subtilisin NAT production by submerged cultivation and three variables/three levels of response surface methodology (RSM) using various inoculum densities, glucose concentrations, and defatted soybean concentrations as the three variables. According to the RSM analysis, while culturing by $2.93 \%$ defatted soybean, $1.75 \%$ glucose, and $4.00 \%$ inoculum density, we obtained an activity of $13.78 \mathrm{SU} / \mathrm{mL}$. Processing the batch fermentation with this optimal condition, the activity reached $13.69 \mathrm{SU} / \mathrm{mL}$, which is equal to $99.3 \%$ of the predicted value.
\end{abstract}

\section{KEYWORDS: Subtilisin NAT; nattokinase; Bacillus subtilis natto; response surface methodology}

\section{INTRODUCTION}

Natto is a traditional fermented food in Japan with a history of more than 1000 years. Its functions for health, including reducing blood cholesterol levels, decreasing blood pressure, and inhibiting osteoporosis, have made it a popular functional food worldwide (1). Accounts of cardiovascular diseases have become the leading cause of death in the Western world (2); many blood clot-dissolving agents, such as urokinase, streptokinase, and tissue plasminogen activator (t-PA), have been utilized in clinical treatments for cardiovascular diseases. However, urokinase and t-PA are very expensive, and t-PA has a short half-life (3); streptokinase is a nonhuman protein and is immunogenic. The most severe defect of these blood clotdissolving agents is the possibility of causing hemorrhagic side effect, which is fatal (4).

Subtilisin NAT (formerly designated nattokinase or subtilisin BSP), produced by Bacillus subtilis natto, is a serine protease (5) and is reported to have potent fibrinolytic activity (6). Besides in vitro tests of fibrinolytic activity, many in vivo studies had been reported. Sumi et al. (7) treated dogs with nattokinase by oral administration, and the fibrinolytic activity in plasma increased. Fujita et al. $(8,9)$ proved that subtilisin NAT could pass the rat intestinal tract and dissolve the chemically induced thrombosis. Suzuki et al. (10) found that dietary supplementation of natto suppressed intimal thickening and modulated the lysis of mural thrombi after endothelial injury in rat femoral artery. Yamashita et al. (11) also reported a similar effect of dietary Bacillus natto productive protein on in vivo endogenous thrombolysis.

* To whom correspondence should be addressed. Tel: +886-233664519. Fax: +886-2-23627044. E-mail: tmpan@ntu.edu.tw.
Similar fibrinolytic enzyme-producing bacteria have also been isolated from Japanese shiokara (12), Korea chungkook-jang (13), and Chinese douchi (14). Nevertheless, it is still the most stable and economic way to obtain protein with fibrinolytic activity by $B$. subtilis natto. On the basis of its food origin, relatively strong fibrinolytic activity, stability in the gastrointestinal tract, and convenient oral administration, subtilisin NAT has advantages for commercially used medicine for preventative and prolonged effects.

Recently, statistical designs, including the Taguchi method and response surface methodology (RSM) $(15,16)$, have been employed to optimize enzyme production. Optimization through factorial design and response surface analysis is a common practice in biotechnology. Various research workers have applied this technique, especially for the optimization of culture conditions (17), such as lipase (18), xylanase (19), and monacolin K (20). In this study, we isolated B. subtilis natto strains from commercial natto products and optimized the culture conditions by RSM to find a simple way to produce subtilisin NAT with a low cost of cultivation. To our knowledge, this is the first paper using a cheap substrate to produce valuable subtilisin NAT.

\section{MATERIALS AND METHODS}

Bacterial Strain and Culture Conditions. B. subtilis natto was isolated from commercial natto collected in supermarkets. Two granules of natto were inoculated into a $50 \mathrm{~mL}$ Hinton flask with $10 \mathrm{~mL}$ of nutrient broth (Difco Laboratories Inc., Detroit, MI); after shaking flask cultivation for $24 \mathrm{~h}$, single colonies were obtained by streaking plates. In this study, we also used various concentrations of defatted soybean combined with glucose as the medium. All shaking flask cultures in this study were maintained in an orbital shaker set at $150 \mathrm{rpm}$ and $37^{\circ} \mathrm{C}$. 
Strain Screening. All strains isolated from commercial natto were further screened by fibrin-plate method (21). Thrombin from bovine plasma (Sigma, St. Louis, MO) solution of $0.5 \mathrm{~mL}(50 \mathrm{NIH} \mathrm{U} / \mathrm{mL})$ was added into $10 \mathrm{~mL}$ of bovine fibrinogen (Sigma) solution [5 mg/ $\mathrm{mL}$ in borate saline buffer $\left(0.01 \mathrm{M} \mathrm{Na}_{2} \mathrm{~B}_{4} \mathrm{O}_{7}, 0.16 \mathrm{M} \mathrm{H}_{3} \mathrm{BO}_{3}\right.$, and 0.04 $\mathrm{M} \mathrm{NaCl}, \mathrm{pH} 7.8)]$ in a Petri dish and kept at room temperature $\left(25^{\circ} \mathrm{C}\right)$ for $1 \mathrm{~h}$ for fibrin clots forming, after which the fibrin plate was ready. Ten microliters of the sample was dropped on the plate and incubated at $37{ }^{\circ} \mathrm{C}$ for $3 \mathrm{~h}$. The relative fibrinolytic activity was determined according to the area of clear zones.

The commercial product that we used was manufactured by a Japanese brand "Okame Natto". In this study, we collected many kinds of products and screened the enzyme activity of each product because there would be more opportunity to find $B$. subtilis natto strain with higher activity. The product with the strongest activity was chosen. The strain that we isolated was than identified as B. subtilis ssp. subtilis by the Food Industry Research and Development Institute (Hsin-chu, Taiwan) according to the results of photomicrograph, 16S rDNA sequencing, and microorganism fatty acid identification system. The identification report number was 97ID017.

Fibrinolytic Activity Determination. The fibrinolytic activity was analyzed by chromogeic method (22). Synthetic substrate (S-2251), H-D-Val-Leu-Lys-pNA (Sigma), was used in fibrinolytic activity determination.

One unit of SU was defined as $1 \mathrm{nmol}$ of $p$-nitroaniline released from substrate S2251 per minute per milliliter. Synthetic substrate (S2251), H-D-Val-Leu-Lys- $p$ NA (Sigma), was used in fibrinolytic activity determination. A $0.2 \mathrm{~mL}$ amount of Tris- $\mathrm{HCl}(0.1 \mathrm{M}$ Tris- $\mathrm{HCl}$ and 0.2 $\mathrm{M} \mathrm{NaCl}, \mathrm{pH} 9.0)$ and $0.1 \mathrm{~mL}$ of sample were mixed and incubated at $37{ }^{\circ} \mathrm{C}$ for $2 \mathrm{~min}$. A substrate solution of $0.2 \mathrm{~mL}(5 \mathrm{mM})$ was added into the mixture and incubated at $37{ }^{\circ} \mathrm{C}$ for $5 \mathrm{~min}$. The reaction was stopped with $0.5 \mathrm{~mL}$ of trichloroacetate $(0.2 \mathrm{M})$. After centrifugation for $5 \mathrm{~min}$ at $10000 \mathrm{~g}$, the supernatant was recovered and measured at $405 \mathrm{~nm}$ to get $A_{1}$. If the reaction was stopped before adding S-2251, then the $A_{405}$ was $A_{0}$. The $p$ NA concentration was determined by the following equation:

$$
\begin{gathered}
\frac{\Delta A_{405} / \mathrm{min}}{\frac{\varepsilon \times 10^{6}}{1} \times 0.1}=\frac{\Delta A_{405} / \mathrm{min}}{\frac{9950 \times 10^{6}}{1} \times 0.1}=201 \times \Delta A_{405} \\
\Delta \mathrm{A} 405: \mathrm{A}_{1}-\mathrm{A}_{0}
\end{gathered}
$$

where $\Delta A_{405}$ is $A_{1}-A_{0}$ and $\epsilon$ is the extinction coeffient of $p \mathrm{NA}$ at $405 \mathrm{~nm}$.

Design of Experiments and Model. RSM is a reliable and useful statistics methodology for investigating the optimal condition. RSM is usually used to investigate the effects of the condition factors on the changes of target product or markers through multiple views provided by a curve surface figure (23). This study used RSM to investigate optimum culture conditions including three factors: defatted soybean concentration, glucose concentration, and inoculum density.

Defatted soybean and glucose were the main nutrients for growing and, accordingly, were chosen as two variables. As for the third, cultivation time, rotation speed of the shaker, inoculum density, etc. might be chosen. However, we found that the cultivation time was not suitable because in different medium conditions, the activity would start to be driven high at similar time points. Also, our pretest showed that the rotation speed of the shaker was not important.

To identify the optimum condition, a Box-Behnken design (24) was selected. The crucial factors considered in this study included defatted soybean concentration $\left(X_{1}\right)$, glucose concentration $\left(X_{2}\right)$, and inoculum density $\left(X_{3}\right)$. These factors, and the level at which the experiments were carried out, are shown in Tables $\mathbf{1}$ and $\mathbf{2}$. A total of 15 runs with central points were generated. The central point of the design arrangement used in this study was a defatted soybean concentration of $3.0 \%$, a glucose concentration of $1.0 \%$, and an inoculum density of $5.0 \%$. Each run of experiments was carried out in a $500 \mathrm{~mL}$ Hinton flask.

RSM. The analysis of data was carried out using response surface regression (RSREG) in statistical analysis system (SAS, Cary, NC). A
Table 1. Process Variables and Levels in the Three Variables/Three Levels Response Surface Design

\begin{tabular}{lcccc}
\hline & & \multicolumn{3}{c}{ coded variable level } \\
\cline { 3 - 5 } \multicolumn{1}{c}{ variable } & symbol & -1 & 0 & 1 \\
\hline defatted soybean (\%) & $\mathrm{X}_{1}$ & 2.0 & 3.0 & 4.0 \\
glucose (\%) & $\mathrm{X}_{2}$ & 0.5 & 1.0 & 1.5 \\
inoculum density (\%) & $\mathrm{X}_{3}$ & 4.0 & 5.0 & 6.0
\end{tabular}

Table 2. Process Variables and Levels in the Three Variables/Three Levels Response Surface Central Composite Design Arrangement

\begin{tabular}{cccc}
\hline runs & defatted soybean $(\%)$ & glucose $(\%)$ & inoculum density $(\%)$ \\
\hline 1 & $4.0(1)$ & $1.5(1)$ & $5.0(0)$ \\
2 & $4.0(1)$ & $0.5(-1)$ & $5.0(0)$ \\
3 & $2.0(-1)$ & $1.5(1)$ & $5.0(0)$ \\
4 & $2.0(-1)$ & $0.5(-1)$ & $5.0(0)$ \\
5 & $4.0(1)$ & $1.0(0)$ & $6.0(1)$ \\
6 & $4.0(1)$ & $1.0(0)$ & $4.0(-1)$ \\
7 & $2.0(-1)$ & $1.0(0)$ & $6.0(1)$ \\
8 & $2.0(-1)$ & $1.0(0)$ & $4.0(-1)$ \\
9 & $3.0(0)$ & $1.5(1)$ & $6.0(1)$ \\
10 & $3.0(0)$ & $1.5(1)$ & $4.0(-1)$ \\
11 & $3.0(0)$ & $0.5(-1)$ & $6.0(1)$ \\
12 & $3.0(0)$ & $0.5(-1)$ & $4.0(-1)$ \\
13 & $3.0(0)$ & $1.0(0)$ & $5.0(0)$ \\
14 & $3.0(0)$ & $1.0(0)$ & $5.0(0)$ \\
15 & $3.0(0)$ & $1.0(0)$ & $5.0(0)$ \\
& & &
\end{tabular}

second-order model was employed to fit the data individually for the responses $\mathrm{Y}$ (fibrinolytic activity) by the general mode (25), with three factors, each coded factor was in the range of $-1,0$, and +1 . The second-order equation is as follows:

$$
\begin{aligned}
Y=A_{0}+A_{1} X_{1}+A_{2} X_{2}+ & A_{3} X_{3}+A_{12} X_{1} X_{2}+A_{13} X_{1} X_{3}+ \\
& A_{23} X_{2} X_{3}+A_{11} X_{1}{ }^{2}+A_{22} X_{2}{ }^{2}+A_{33} X_{3}^{2}
\end{aligned}
$$

$X_{1}, X_{2}$, and $X_{3}$ are the three variables in the model, and this secondorder equation was employed to fit the data individually for the responses $Y$. It means that this equation figures and simulates the results of various combinations of cultivation conditions. After 15 runs of central composite design arrangement, we can obtain the coefficients of this equation $\left(A_{0}, A_{1}, A_{2}, A_{3}, A_{12}\right.$, etc.) by statistical software.

Batch Fermentation. Batch fermentation was carried out using a $500 \mathrm{~mL}$ Hinton flask. Cell cultures were first grown overnight and inoculated into $250 \mathrm{~mL}$ flasks containing fresh nutrient broth (Difco Laboratories Inc.). After $12 \mathrm{~h}$, the seeding culture was transferred into a $500 \mathrm{~mL}$ Hinton flask to a final volume of $100 \mathrm{~mL}$ and maintained in an orbital shaker set at $150 \mathrm{rpm}$ and $37^{\circ} \mathrm{C}$.

\section{RESULTS}

Strain Screening. Among 34 strains of B. subtilis natto, strain 12-1-2 harbored the largest clear zone (data not shown). This strain was further identified and confirmed by Food Industry Research and Development Institute (Hsin-chu, Taiwan).

Only the supernatant of fermented samples was detected in the fibrin plate test. Each sample would cause a clear zone on the plate, and the area was measured for relative comparison.

Confirmation of Subtilisin NAT. Nattokinase (subtilisin NAT) digested not only fibrin but also the plasmin substrate H-D-Val-Leu-Lys-pNA (S-2251), which was more sensitive to the enzyme than other substrates tried (6). To confirm whether it was subtilisin NAT, the chromosomal DNA of the strain was extracted, and then, the DNA of subtilisin NAT was amplified by polymerase chain reaction (PCR). Figure 1 was the result of electrophoresis, showing that its length was about $1100 \mathrm{bp}$, which was a correct length (26). The sequence was further 


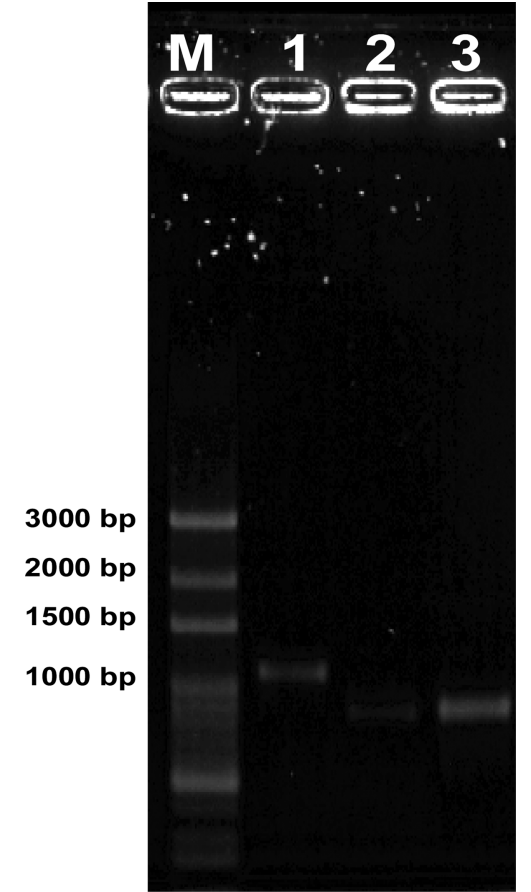

Figure 1. Molecular cloning of various lengths of apN gene by PCR. Lane M, 100 bp DNA ladder; lane 1, PCR product of pro-NK; lane 2, PCR product of mature NK; and lane 3, PCR product of NK-histag.

confirmed by Mission Biotech (Taipei, Taiwan) and was completely the same as the $a p r \mathrm{~N}$ gene, which encodes subtilisin NAT.

Central Points of RSM. In RSM, the central points of each condition were studied at first. As shown in Figure 2a, while glucose concentration and inoculum density were set at 1.0 and $3.0 \%$, respectively, $3.0 \%$ of defatted soybean would obtain the highest enzyme activity. In Figure $\mathbf{2 b}$, both defatted soybean concentration and inoculum density were set at $3.0 \% ; 1.0 \%$ of glucose would obtain the largest activity. In Figure 2c, the highest activity was obtained when the inoculum density was $5.0 \%$, and concentrations of defatted soybean and glucose were set at 3.0 and $1.0 \%$, respectively. Each best concentration of different conditions was chosen as central points.

Regression Equation, $\boldsymbol{r}^{\mathbf{2}}$ Value of Model. Data from 15 experiments were used to determine the regressional equation in which the factors were obtained from regressional analysis for the subtilisin NAT activity: fibinolytic activity $=94.99+$ $16.29 X_{1}-18.84 X_{2}+2.75 X_{3}-28.65 X_{1} X_{2}+0.78 X_{2} X_{3}+$ $12.95 X_{1}^{2}-5.49 X_{2}^{2}$. The variability in the responses was accounted for by the factor $\left(r^{2}\right.$ value) for the model, and the data are given in Table 3. The $r^{2}$ value of fibrinolytic activity was 0.87. Also, the $p$ value for the overall regression is significant at the 5\% level, which indicates that the model is adequate in approximating the response surface of the experimental design.

Effects of Different Culture Conditions. As shown in Figure 3, in accordance with the regressional equation, response surfaces were obtained by SPSS (SPSS Taiwan Co., Taipei, Taiwan) and Sigma Plot 8.0 (Aspire Software International, Ashburn, VA). The highest activity was situated on the lower response surface in which the inoculum density was $4.0 \%$. Because the response surfaces were constituted by continuous responses of various conditions, we could not show all of the results on the plot. However, according to the mathematics (a)
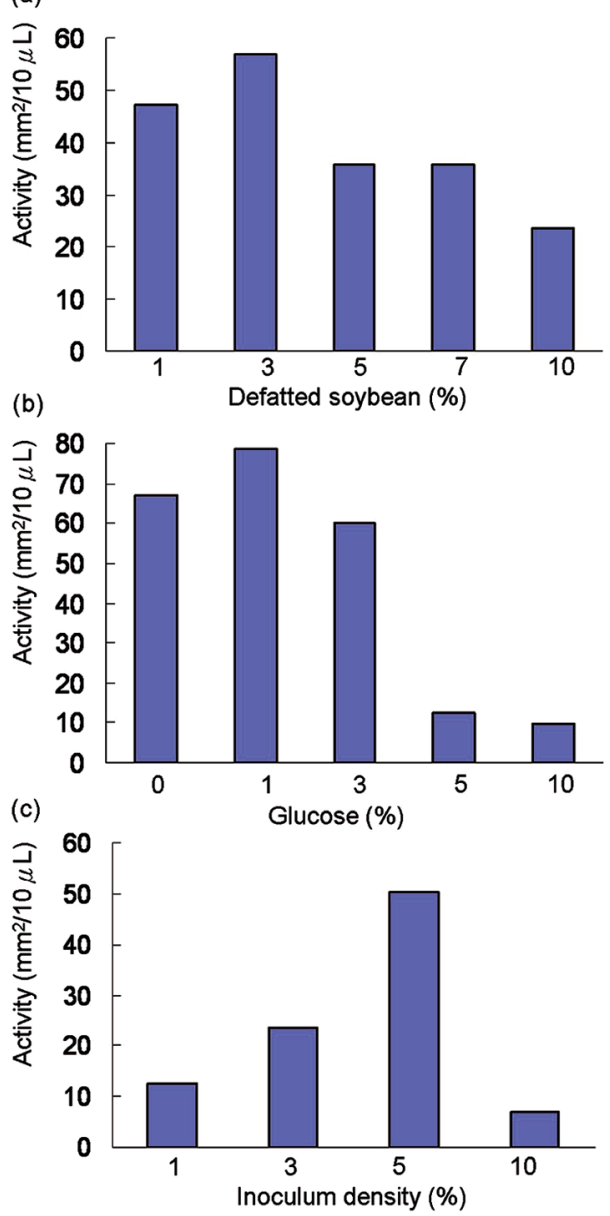

Figure 2. Effects of various factors in RSM. (a) Defatted soybean concentration, (b) glucose concentration, and (c) inoculum density.

Table 3. Analysis of Variances for the Activity of Subtilisin NAT with Various Culture Conditions

\begin{tabular}{lcc}
\hline & & sum of square \\
\cline { 3 - 3 } source & degrees of freedom & activity \\
\hline regression & 9 & 126.0 \\
residual & 5 & 19.0 \\
lack of fit & 3 & 17.0 \\
pure error & 2 & 2.0 \\
variability $\left(r^{2}\right)$ & & 0.87 \\
\end{tabular}

operated by software, the optimal condition was $2.93 \%$ defatted soybean, $1.75 \%$ glucose, and $4.00 \%$ inoculum density, and the activity was expected to reach $13.78 \mathrm{SU} / \mathrm{mL}$.

Optimal Batch Fermentation. The batch fermentation was performed by the optimum medium using a $500 \mathrm{~mL}$ Hinton flask. As shown in Figure 4, the log phase started from the sixth hour and stopped at the 12th hour, the beginning of the stationery phase. After $24 \mathrm{~h}$, viable cells reached $2.88 \times 10^{9}$ $\mathrm{CFU} / \mathrm{mL}$. The enzyme activity appeared at the ninth hour and continuously increased before the 24th hour. After the 24th hour, it reached the highest activity at the 34th hour and sustained through the rest of the time of cultivation. The highest activity detected was $13.69 \mathrm{SU} / \mathrm{mL}$, reaching $99.3 \%$ of predicted value.

\section{DISCUSSION}

Subtilisin NAT has been proved to have strong fibrinolytic activity. There are many advantages, including its food origin and safety, to apply subtilisin NAT to thrombosis therapy. 

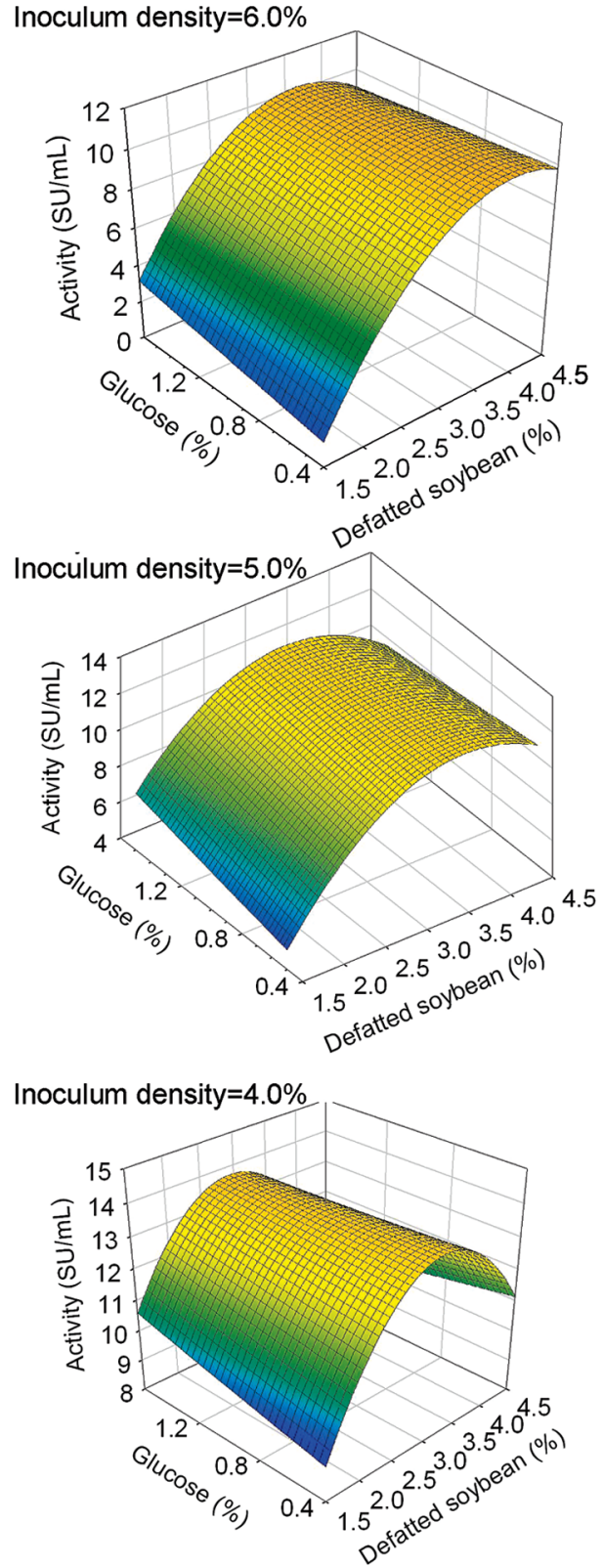

Figure 3. Response surfaces for the activity of subtilisin NAT produced by $B$. subtilis natto 12-1-2 submerged culture at various concentrations of defatted soybean, glucose, and inoculum density.

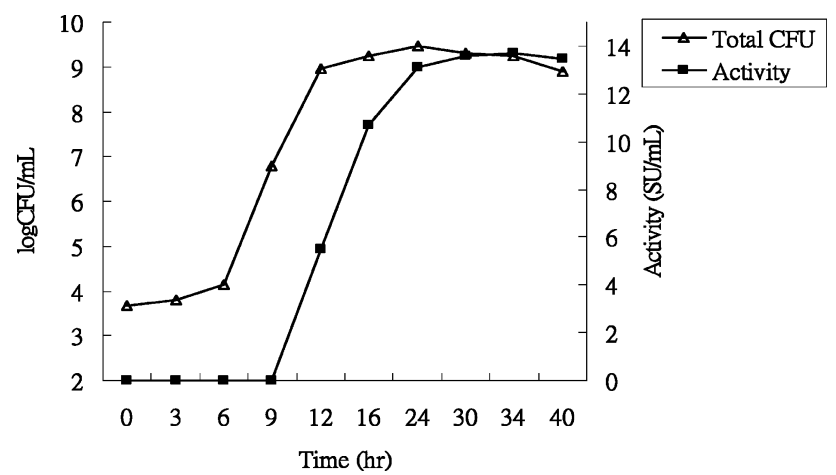

Figure 4. Time course for batch culture of $B$. subtilis natto 12-1-2 in a $500 \mathrm{~mL}$ Hinton flask with the optimal condition obtained by RSM. The cultural temperature was maintained at $37^{\circ} \mathrm{C}$, and the rotary shaker was set at $150 \mathrm{rpm}$.

Recently, many genetic engineering methods, for example, heterologous expression by Escherichia coli or Spodoptera
Table 4. Studies of Nattokinase Production ${ }^{a}$

\begin{tabular}{lcl}
\hline nattokinase-producing strains or cells & activity & ref \\
\hline & $U$ & \\
B. subtilis from thua nao & $9.6 \mathrm{U} / \mathrm{mL}$ & $(29)$ \\
recombinant S. frugiperda cells & $60.0 \mathrm{U} / \mathrm{mL}$ & $(28)$ \\
recombinant . coli & $260.0 \mathrm{U} / \mathrm{mL}$ & $(30)$ \\
B. subtilis var. natto & $3109.0 \mathrm{U} / \mathrm{mg}$ & $(31)$ \\
& $\mathrm{CU}$ & \\
recombinant B. subtilis & $71500.0 \mathrm{CU} / \mathrm{mL}$ & $(32)$ \\
& $\mathrm{SU}$ & \\
B. subtilis ssp. subtilis 168 & $11.10 \mathrm{SU} / \mathrm{mL}$ & (33) \\
B. subtilis from natto & $13.69 \mathrm{SU} / \mathrm{mL}$ & this study
\end{tabular}

${ }^{a} \mathrm{U}$, activity detected using urokinase as a standard; $\mathrm{CU}$, activity detected using $\alpha$-casein as a substrate; and SU, activity detected using S-2251 as a substrate.

frugiperda cells, of producing subtilisin NAT have been reported $(27,28)$.

However, low expression efficiency of recombinant hosts, low yield, and instability of recombinant subtilisin NAT confine it to the application of industrial scale production. In this study, avoiding uncertainty of genetic engineering, we utilized $B$. subtilis natto and RSM to optimize the medium composed of defatted soybean, a byproduct in salad oil manufacturing, and glucose, a very common and cheap carbon source.

In our results of RSM, as shown in Figure 3, a higher inoculum density would cause the decrease of the enzyme activity, and decreasing defatted soybean concentration would cause the enzyme activity to drop dramatically. The activity would be decreased to less than $70 \%$ when the inoculum density reached $6.0 \%$. Less seeding culture would generate more viable cells with a higher ability to produce the enzyme.

While under conditions of low defatted soybean concentration, the activity increased with glucose concentration, and this trend became more obvious in low inoculum density. However, under high defatted soybean concentrations, the glucose concentration had less of an effect on the activity. Consequently, defatted soybean played a more important role in the cultivation. In the optimal batch fermentation, $B$. subtilis natto grew stably in the medium and with fibrinolytic activity as expected.

As shown in Table 4, much research about subtilisin NAT production has been reported. Omura et al. (33) also reported correspondence results by adding glucose into soybean milk. In this study, we utilized defatted soybean to be the main origin of nutrition, using less runs of the experiment to optimize the culture condition.

The most important advantage is the low cost of defatted soybean and glucose. The costs per kilogram of nutrient broth (Difco Laboratories Inc.), glucose (Sigma), and defatted soybean were NT 6400, NT 320, and NT 30, respectively. Consequently, the cost of $1 \mathrm{~L}$ of the optimal medium $(29.5 \mathrm{~g}$ of defatted soybean and $17.5 \mathrm{~g}$ of glucose) in this study is less than $13 \%$ of $1 \mathrm{~L}$ of nutrient broth $(8 \mathrm{~g} / \mathrm{L})$. Defatted soybean is a suitable ingredient in the cultivation and production of $B$. subtilis natto and subtilisin NAT. To our knowledge, this paper is the first one using cheap substrates to produce valuable subtilisin NAT.

\section{LITERATURE CITED}

(1) Milner, M.; Makise, K. Natto and its active ingredient nattokinase-A potent and safe thrombolytic agent. Altern. Complementary Ther. 2002, 8, 157-194.

(2) Viles-Gonzalez, J. F.; Fuster, V.; Badimon, J. J. Atherothrombosis: A widespread disease with unpredictable and life-threatening consequences. Eur. Heart J. 2004, 25, 1197-1207. 
(3) Wu, X. C.; Ye, R.; Duan, Y.; Wong, S. L. Engineering of plasminresistant forms of streptokinase and their production in Bacillus subtilis: Streptokinase with longer functional half-life. Appl. Environ. Microbiol. 1998, 64, 824-829.

(4) Rouf, S. A.; Moo-Young, M.; Chisti, Y. Tissue-type plasminogen activator: Characteristics, applications and production technology. Biotechnol. Adv. 1996, 14, 239-266.

(5) Kamata, H.; Yamagata, T.; Nakamura, T.; Nakajima, T.; Oda, K.; Murao, S.; Ichishima, E. Characterization of the complex between $\alpha_{2}$-macroglobulin and a serine proteinase from Bacillus natto. Agric. Biol. Chem. 1989, 53, 2695-2702.

(6) Sumi, H.; Hamada, H.; Tsushima, H.; Mihara, H.; Muraki, H. A novel fibrinolytic enzyme (nattokinase) in the vegetable cheese natto; a typical and popular soybean food in the Japanese diet Experientia 1987, 43, 1110-1111.

(7) Sumi, H.; Hamada, H.; Nakanishi, K.; Hiratani, H. Enhancement of the fibrinolytic activity in plasma by oral administration of nattokinase. Acta. Haematol. 1990, 84, 139-143.

(8) Fujita, M.; Hong, K.; Ito, Y.; Misawa, S.; Takeuchi, N.; Kariya, K.; Nishimuro, S. Transport of nattokinase across the rat intestinal tract. Biol. Pharm. Bull. 1995, 18, 1194-1196.

(9) Fujita, M.; Hong, K.; Ito, Y.; Fujii, R.; Kariya, K.; Nishimuro, S. Thrombolytic effect of nattokinase on a chemically induced thrombosis model in rat. Biol. Pharm. Bull. 1995, 18, 1387-1391.

(10) Suzuki, Y.; Kondo, K.; Ichise, H.; Tsukamoto, Y.; Urano, T.; Umemura, K. Dietary supplementation with fermented soybeans suppresses intimal thickening. Nutrition 2003, 19, 261-264.

(11) Yamashita, T.; Oda, E.; Giddings, J. C.; Yamamoto, J. The effect of dietary Bacillus natto productive protein on in vivo endogenous thrombolysis. Pathophysiol. Haemostasis Thromb. 2003, 33, 138 143.

(12) Sumi, H.; Nakajima, N.; Yatagai, C. A unique strong fibrinolytic enzyme (katsuwokinase) in shipjack "Shiokara", a Japanese traditional fermented food. Comp. Biochem. Physiol., Part B: Biochem. Mol. Biol. 1995, 112B, 543-547.

(13) Kim, W.; Choi, K.; Kim, Y.; Park, H.; Choi, J.; Lee, Y.; Oh, H.; Kwon, I.; Lee, S. Purification and characterization of a fibrinolytic enzyme produced from Bacillus sp. strain CK11-4 screened from Chungkoo-Jang. Appl. Environ. Microbiol. 1996, 62, 2482-2488.

(14) Peng, Y.; Huang, Q.; Zhang, R. H.; Zhang, Y. Z. Purification and characterization of a fibrinolytic enzyme produced by Bacillus amyloliquefaciens DC-4 sceened form douche, a traditional Chinese soybean food. Comp. Biochem. Physiol., Part B: Biochem. Mol. Biol. 2003, 134, 34-52.

(15) Heravi, K.; Eftekhar, F.; Yakhchali, B.; Tabandeh, F. Isolation and identification of a lipase producing Bacillus sp. from soil. Pak. J. Biol. Sci. 2008, 11, 740-745.

(16) Lee, C. L.; Chen, W. P.; Wang, J. J.; Pan, T. M. A simple and rapid approach for removing citrinin while retaining monacolin $\mathrm{K}$ in red mold rice. J. Agric. Food Chem. 2007, 55, 11101-11108.

(17) Kalil, S. J.; Maugeri, F.; Rodrigues, M. I. Response surface analysis and simulation as a tool for bioprocess design and optimization. Process. Biochem. 2000, 35, 539-550.

(18) Rathi, P.; Goswami, V. K.; Sahai, V.; Gupta, R. Statistical medium optimization and production of a hyperthermostable lipase from Burkholderia cepacia in a bioreactor. J. Appl. Microbiol. 2002, 93, 930-936.
(19) Park, Y. S.; Kang, S. W.; Lee, J. S.; Hong, S. I.; Kim, S. W. Xylanase production in solid state fermentation by Aspergillus niger mutant using statistical experimental designs. Appl. Microbiol. Biotechnol. 2002, 58, 761-766.

(20) Lee, C. L.; Hung, H. K.; Wang, J. J.; Pan, T. M. Improving the ratio of monacolin $\mathrm{K}$ to citrinin production of Monascus purpureus NTU 568 under dioscorea medium through the mediation of $\mathrm{pH}$ value and ethanol addition. J. Agric. Food Chem. 2007, 55, 64936502.

(21) Astrup, T.; Müllertz, S. The fibrin plate method for estimating fibrinolytic activity. Arch. Biochem. Biophys. 1952, 40, 346-351.

(22) Friberger, P.; Knos, M.; Gustavsson, S.; Aurell, L.; Claeson, G. Methods for determination of plasmin, antiplasmin and plasminogen by means of substrate S-2251. Haemostasis 1978, 7, 138145.

(23) Wang, J. J.; Lee, C. L.; Pan, T. M. Improvement of monacolin $\mathrm{K}$, gamma-aminobutyric acid and citrinin production ratio as a function of environmental conditions of Monascus purpureus NTU 601. J. Ind. Microbiol. Biotechnol. 2003, 30, 669-676.

(24) Box, G. E. P.; Behnken, D. W. Some new three level designs for the study of quantitative variable. Technometrics 1960, 2, 455463.

(25) Giovanni, M. Response surface methodology and product optimization. Food Technol. 1983, 37, 96-105.

(26) Nakamura, T.; Yamagata, Y.; Ichishima, E. Nucleotide sequence of the subtilisin NAT gene, aprN, of Bacillus subtilis (natto). Biosci., Biotechnol., Biochem. 1992, 56, 1869-1871.

(27) Chiang, C.; Chen, H.; Chao, T.; Tzen, J. Efficient system of artificial oil bodies for functional expression and purification of recombinant nattokinase in Escherichia coli. J. Agric. Food Chem. 2005, 53, 4799-4804.

(28) Li, X.; Wang, X.; Xiong, S.; Zhang, J.; Cai, L.; Yang, Y. Expression and purification of recombinant nattokinase in Spodoptera frugiperda cells. Biotechnol. Lett. 2007, 29, 14591464.

(29) Inatsu, Y.; Nakamura, N.; Yuriko, Y.; Fushimi, T.; Watanasiritum, L.; Kawamoto, S. Characterization of Bacillus subtilis strains in Thua nao, a traditional fermented soybean food in northern Thailand. Lett. Appl. Microbiol. 2006, 43, 237-242.

(30) Liang, X.; Jia, S.; Sun, Y.; Chen, M.; Chen, X.; Zhong, J.; Huan, L. Secretory expression of nattokinase from Bacillus subtilis YF38 in Escherichia coli. Mol. Biotechnol. 2007, 37, 187-194.

(31) Wu, S.; Feng, C.; Zhong, J.; Huan, L. Roles of s3 site residues of nattokinase on its activity and substrate specificity. J. Biochem. 2007, 142, 357-364.

(32) Chen, P. T.; Chiang, C. J.; Chao, Y. P. Medium optimization for the production of recombinant nattokinase by Bacillus subtilis using response surface methodology. Biotechnol. Prog. 2007, 23, $1327-1332$.

(33) Omura, K.; Hitosugi, M.; Zhu, X.; Ikeda, M.; Maeda, H.; Tokudome, S. A newly derived protein from Bacillus subtilis natto with both antithrombotic and fibrinolytic effects. J. Pharmacol. Sci. 2005, 99, 247-251.

Received for review August 3, 2008. Revised manuscript received October 8, 2008. Accepted November 11, 2008.

JF8024198 